\title{
PERSEPSI ATLET TERHADAP TINGKAT KELELAHAN PADA MULTISTAGE FITNESS TEST DAN YO-YO INTERMITTEND RECOVERY TEST
}

\author{
Oleh: \\ Loly Zulfiyani dan Eka Novita Indra \\ Pendidikan Kesehatan dan Rekreasi FIK UNY
}

\begin{abstract}
Abstrak
Yo-yo intermittent recovery test digunakan oleh pelaku olahraga sebagai alat ukur Vo2max khususnya pada cabang olahraga permainan yangcepat dan explosivesecara intermittend. Tipe latihan yang digunakan oleh atlet basket menggunakan kecepatan yang explosive dalam berlari lalu beristirahat aktif sambil dribbling, passing, shooting ataupun berfikir untuk membuat strategi, oleh sebab itu yo-yo intermittent recovery testsangat valid dilakukan pada cabang olahraga bola basket. Tujuan penelitian ini adalah untuk mengetahui persepsi atlet terhadap tingkat kelelahan pada multistage fitness test dan yo-yo intermittend recovery test di tim basket putra SMA Negeri 4 Yogyakarta.

Penelitian ini adalah penelitian deskriptif persentase dan metode yang digunakan dalam penelitian ini adalah metode survei dengan teknik tes dan pengukuran untuk mengambil data. Hasil penelitian adalah: Indeks persepsi kelelahan tim basket putra SMA Negeri 4 Yogyakarta terhadap tes daya tahan paru jantung metode multistage fitness test yang berada dalam skala skala 11 (ringan) sebesar 7,7\%, skala 13 (sedang) sebesar 30,8\%, skala 15 (berat) sebesar 53,8\%, skala 17 (sangat berat) sebesar 7,7\%.Indeks persepsi kelelahan tim basket putra SMA Negeri 4 Yogyakarta terhadap tes daya tahan paru jantung metode yo-yo intermittend recovery test yang berada dalam skala 13 (sedang) sebesar 38,4\%, skala 15 sebesar 53,8\%, skala 17 sebesar 7,7\%.
\end{abstract}

\section{Kata Kunci: Tingkat Kelelahan, Multistage FitnessTest, dan Yo-Yo Intermittend Recovery Test}

Persepsi kelelahan merupakan respon yang dialami oleh seseorang yang mengalami suatu stimulus pada indra-indra yang terdapat dalam tubuh. Persepsi juga dapat dikatakan sebagai suatu pandangan pribadi seseorang terhadap sesuatu yang dirasakan. Persepsi yang baik pada atlet perlu dibangun untuk membuat pandangan yang positif terhadap suatu stimulus yang dirasakannya. Persepsi kelelahan dapat dikatakan sebagai unsur psikologi yang dapat diukur. Psikologi berhubungan dengan pikiran, perasaan dan emosi atlet yang biasanya disebut dengan mental. Hal ini berhubungan dengan motivasi, kepercayaan diri dan emosi yang dapat mempengaruhi performa dan perilaku atlet baik dilatihan maupun pertandingan. Program peningkatan mental atlet merupakan salah satu program yang penting yang dibuat oleh pelatih. Permainan bola basket dimainkan oleh 2 tim yang masing-masing tim berjumlah 5 orang. Permainan bola basket bertujuan untuk memasukkan bola ke dalam basket atau 
keranjang lawan dengan sebanyak-banyaknya. Peraturan PERBASI (2010: 12) menerangkan, pertandingan akan terdiri dari empat (4) periode dengan masing-masing periode sepuluh (10) menit, dengan begitu dapat memacu kerja jantung, pernapasan pada paru-paru, dan daya tahan otot lokal.

Instensitas yang digunakan pada permainan ini cukup tinggi, dikarenakan permainan ini harus melakukan teknik dasar passing, dribbling, jumping, dan shooting dalam waktu yang singkat agar bola tidak dapat dikuasai oleh tim lawan. Komponen kebugaran jasmani yaitu kecepatan juga mengalami peningkatan disebabkan tuntutan kerja yang mengharuskan setiap teknik dasar dilakukan dengan cepat. Hal ini sudah diatur dalam peraturan resmi bola basket yang mengharuskan atlet bergerak cepat dalam waktu 24 detik selama berada dalam wilayah penyerangan atau 3 detik berada dalam pertahanan lawan dan juga mengharuskan atlet pulang dan pergi dalam waktu singkat.

Tes kebugaran jasmani penting dilakukan agar diketahui seberapa besar kemampuan kebugaran jasmani yang dimiliki oleh atlet. Hasil dari tes kebugaran jasmani dapat dijadikan sebagai acuan dalam mengevaluasi kekuatan dan kelemahan yang dimiliki oleh atlet, sehingga para pelaku olahraga khususnyapelatih disemua tingkatan pembinaan baik di klub, universitas atau di sekolah dapat meningkatkan performa permainan atlet dan membuat program latihan yang paling tepat dalam mencapai prestasi. Salah satu komponen kebugaran jasmani yang dapat diukur melalui tes kebugaran jasmani adalah daya tahan paru jantung yang biasa disebut juga dengan VO2 Max. Alat untuk mengukur tes VO2 Max harus diciptakan dengan sedemikian rupa sehingga tekanan pada pasokan oksigen ke otot jantung harus berlangsung maksimal. Beberapa cara untuk mengetahui kemampuan kapasitas VO2 Max dengan melakukan tes kebugaran jasmani, seperti: tes Rockport, $2.4 \mathrm{~km}$ Run Test, tes Astrand 6 minutes cycle, tes Balke, tes Cooper, tes Harvard step, treadmill VO2 Max test, musltistage fitness testdan yo-yo intermittent recovery test.

Yo-yo intermittent recovery test merupakan perkembangan dari multistage fitnest test. Yo-yo intermittent recovery test memiliki kesamaan dengan multistage fitnest testdari tata pelaksanaannya yang mengharuskan peserta tes berlari di lintasan sepanjang $20 \mathrm{~m}$ dengan mengikuti aba-aba dari cd audio, perbedaan yang mencolok terletak pada jeda istirahat dan percepatan. Yo-yo intermittent recovery testmengharuskan peserta untuk berlari lalu beristirahat aktif selama 10 detik, sedangkan pada multistage fitnest testpeserta berlari tanpa jeda istirahat dengan percepatan yang bertambah dengan perlahan pada setiap levelnya. Berdasarkan permasalahan yang telah dijabarkan tersebut peneliti tertarik untuk melakukan 
penelitian analisis persepsi terhadap tingkat kelelahan pada multistage fitness test dan yo-yo intermittend recovery test. Penelitian ini dapat dijadikan sebagai bahan acuan untuk mengevaluasi kemampuan daya tahan paru jantung atlet agar dapat memperoleh prestasi yang lebih tinggi.

\section{KAJIAN PUSTAKA}

\section{Persepsi terhadap Kelelahan Otot}

Menurut Santosa Giriwijoyo dan Dikdik Zafar Sidik (2012: 51), kelelahan dapat didefinisikan sebagai kondisi menurunnya kapasitas kerja yang disebabkan oleh melakukan pekerjaan. Kelelahan otot merupakan suatu keadaan yang terjadi setelah kontraksi otot yang kuat dan lama, dimana otot tidak mampu lagi berkontraksi dalam jangka waktu tertentu. Kelelahan otot menunjuk pada suatu proses yang mendekati definisi fisiologik yang sebenarnya yaitu berkurangnya respons terhadap stimulasi yang sama. Mekanisme yang berperan dalam menjelaskan kelelahan telah diklasifikasikan secara umum sebagai akumulasi produk dan deplesi substrat. Kelelahan otot secara umum dapat dinilai berdasarkan persentase penurunan kekuatan otot, waktu pemulihan kelelahan otot, serta waktu yang diperlukan sampai terjadi kelelahan (Yoghi Prawira Utama, 2010: 2).

Faktor penyebab kelelahan sangat kompleks, baik itu berasal dari kondisi fisiologis maupun kondisi psikologis atlet. Timbulnya kelelahan otot pada waktu berolahraga dapat disebabkan berbagai hal antara lain: menipisnya cadangan energi yang berasal dari ATP, kreatin fosfat, glikogen atau glukosa; akumulasi laktat di otot; gangguan homeostatis, misalnya gangguan osmolaritas plasma, volume plasma, penurunan $\mathrm{pH}$ cairan tubuh, dan penurunan kadar elektrolit cairan tubuh; kelelahan akibat gangguan neuromuskular atau sentral; kelelahan yang diakibatkan oleh kondisi lingkungan, baik itu suhu maupun kelembaban udara; dan karena terjadinya akumulasi asam laktat dalam otot sebagai hasil glikolisis anaerobik (Novita Intan Arovah, dkk: 2010).

\section{Hakikat Kebugaran Jasmani}

Menurut Djoko Pekik Irianto (2004: 10), kebugaran jasmani kebugaran fisik (physical fitness), yakni kemampuan seseorang melakukan kerja sehari-hari secara efisien tanpa timbul kelelahan yang berlebihan sehingga dapat menikmati waktu luangnya. Banyak sekali atlet yang menjalani sesi latihan yang berat sehingga mengalami proses pemulihan yang lambat. Namun bagi atlet yang memiliki kebugaran jasmani yang tinggi, proses 
pemulihan tersebut akan berjalan dengan cepat sehingga atlet dapat menikmati waktu senggang yangdimiliki.

Tes kebugaran jasmani merupakan suatu instrumen atau alat yang digunakan untuk mengukur kemampuan seseorang yang berkaitan dengan komponen-komponen kebugaran jasmani. Menurut Andi Suntoda (2009: 1), tes adalah suatu alat ukur atau instrumen yang digunakan untuk memperoleh informasi/ data tentang seseorang atau obyek tertentu. Data yang diperoleh merupakan atribut atau sifat-sifat yang melekat pada individu atau objek yang bersangkutan. Data yang terhimpun meliputi ranah kognitif, afektif, dan motorik. Data yang bersifat kognitif dijaring melalui tes tulis (essay, obyektif) dan lisan; data bersifat afektif dapat dihimpun melalui tes bentuk skala sikap, angket, dan observasi secara langsung terhadap obyek yang akan diukur; data yang bersifat motorik dapat dihimpun misalnya melalui tes kemampuan dan gerak dasar, fungsional, dan tes keterampilan cabang olahraga. Tes kebugaran jasmani sebaiknya dilakukan pada pagi hari karena suhu udara belum terlalu panas (Suharjana, 2013: 175). Jika dalam keadaan terpaksa tes kebugaran jasmani dapat dilakukan di sore hari. Tes kebugaran jasmani bagi atlet berbeda-beda sesuai dengan kebutuhan fisik cabang olahraga yang bersangkutan. Peserta tes harus dipastikan terlebih dahulu dalam keadaan sehat dan tidak sedang dalam kondisi kelelahan.

\section{Hakikat Bola Basket}

PERBASI (2010: 41), menyatakan bola basket adalah permainan yang dimainkan oleh dua regu yang masing-masing terdiri dari lima orang. Tim terdiri dari dua belas permain termasuk kapten. Bola basket dimainkan oleh dua tim yang masing-masing terdiri dari lima orang atlet. Menguasai teknik dasar merupakan modal utama setiap pemain untuk mencapai prestasi tinggi. Menurut Imam Sodikun (1992: 47) agar kemampuan individual setiap pemain bola basket terlihat bagus maka setiap pemain diharuskan menguasai teknik dasar permainan bola basket. Ada beberapa teknik dasar dalam permainan bola basket yang harus dikuasai oleh seorang pemain diantaranya:

1) Teknik Mengumpan dan Menangkap (Passing dan Catching)

Passing dan Catching merupakan kecakapan dwi tunggal, untuk dapat menghidupkan permaianan bola basket. Istilah melempar mengandung pengertian mengoper bola dan menangkap berarti menerima bola. Melempar dan menangkap bola selalu dilakukan secara berteman, apabila seorang pemain memegang bola maka dia harus melempar bola sedangkan pemain dalam posisi tidak memegang bola maka 
dia bersiap untuk menerima atau menangkap bola (Imam Sodikun,1992: 48). Menurut Wissel (2000: 71) mengumpan memiliki kegunaan khusus, yaitu (a) mengalihkan bola dari daerah padat pemain, (b) menggerakkan bola bola dengan cepat dengan cepat pada fast break, (c) membangun permainan yang ofensif, (d) mengoper ke rekan yang sedang terbuka untuk penembakan, dan (e) mengoper dan memotong untuk melakukan tembakan sendiri.

2) Teknik Menembak (Shooting)

Menurut PERBASI (2010: 18) menembak adalah gerakan terakhir untuk mendapatkan angka. Umumnya dalam bola basket, tembakan dilakukan setiap 15-20 detik dan hampir setengahnya berhasil masuk. Menurut Danny Kosasih (2008: 46-47) shooting adalah skill dasar bola basket yang paling dikenal dan paling digemari. Wissel (2000: 43) mengungkapkan bahwa kemampuan yang harus dikuasai seorang pemain adalah kemampuan memasukkan bola atau shooting. Hal ini sesuai dengan tujuan permainan bola basket yang mengharuskan bagi setiap tim untuk memsukkan bola sebanyak-banyaknya ke basket atau keranjang lawan dan mencegah pihak lawan melakukan hal yang serupa. Kemampuan suatu tim dalam melakukan tembakan akan mempengaruhi hasil yang dicapai dalam suatu pertandingan. Menembak adalah keahlian yang sangat penting di dalam olahraga bola basket, teknik dasar seperti operan, dribbling, bertahan, dan rebounding akan mengantar memperoleh peluang besar membuat skor, tapi tetap saja harus melakukan tembakan. Sebetulnya menembak dapat menutupi kelemahan teknik dasar lainnya. Imam Sodikun (1992:94) mengemukakan bahwa menembak merupakan sasaran akhir setiap pemain dalam bermain. Keberhasilan suatu regu dalam permainan selalu ditentukan oleh suatu keberhasilan dalam menembak.

3) Teknik Menggiring (Dribbling)

Menurut Wissel (2000: 95) drible merupakan bagian yang tak terpisahkan dalam bola basket dan penting untuk permainan individual dan tim. Menurut Imam Sodikun (1992: 57) menggiring bola adalah salah satu cara yang diperbolehkan oleh peraturan untuk membawa lari ke segala arah. Untuk menjelajahi seluruh lapangan dengan bola, perlu kemampuan dribbling yang tinggi. Menurut Perbasi (2010:18) dribble adalah cara untuk bergerak dengan bola yang dilakukan oleh seorang pemain, tujuanya untuk membebaskan diri dari lawan atau mencari posisi yang baik untuk melakukan passing ataupun shooting. Menurut Imam Sodikun (1992: 57) dribbling dapat dilakukan 
dengan bola yang tinggi untuk kecepatan dan bola yang rendah untuk kontrol atau penguasaan bola. Seorang pemain boleh membawa bola lebih dari satu langkah asal bola diambil sambil dipantulkan, baik itu jalan kaki maupun sambil berlari. Pada awalnya bola harus lepas dari tangan sebelum kaki diangakat dari lantai, sementara saat menggiring bola tangan tidak boleh menyentuh bola secara bersamaan atau bola diam dalam genggaman tangan.

Manfaat men-dribble antara lain: a) memindahkan bola keluar dari daerah yang padat penjagaan ketika operan tidak memungkinkan, ketika penerima tidak bebas penjagaan, dan pada saat fast break untuk mencetak angka, b) menembus penjagaan ke arah ring, c) menarik perhatian penjaga untuk membebaskan rekan tim, d) memperbaiki posisi atau sudut, e) membuat peluang untuk mencetak angka (Wissel, 2000: 95).Menurut Wissel (2000: 96) untuk menjadi pemain yang efektif, pemain harus ahli dalam men-dribble dengan tangan manapun. Buatlah bola menjadi perpanjangan tangan, tegakkan kepala untuk mlihat seluruh lapangan. Gerakan dasar men-dribble terdiri dari control dribble, speed dribble, footfire dribble, change-ofpace dribble, retreat dribble, croos-over dribble, inside-out dribble, dan behind-theback dribble. Sedangkan menurut Danny Kosasih (2008: 38) gerakan-gerakan mendribble yang umum digunakan oleh pemain yaitu low dribble, power dribble, speed dribble, change-of-pace dribble, croos-over dribble, head and shoulders move, head and shoulders croosover move, revers/spin dribble, back drbble, behind the back dribble, dan beetwen the legs dribble.

\section{Komponen-Komponen Kebugaran Jasmani yang Berkaitan dengan Keterampilan pada Permainan Bola Basket}

Kemampuan fisik merupakan modal dasar yang harus dimiliki seorang atlet untuk mengembangkan bakat yang telah dimilikinya. Kebugaran jasmani pada olahraga permainan bola basket memiliki banyak komponen-komponen yang harus dimiliki. Salah satu komponen tersebut adalah kemampuan daya tahan paru jantung atau VO2 Max. Menurut Bompa (1994: 27), sistem energi yang digunakan pada olahraga bola basket $80 \%$ menggunakan sistem energi ATP/PC system (anaerobic alactit or phospagen system). Hal ini dapat dilihat dari jenis latihan yang digunakan. Atlet diharuskan melakukan penyerangan dengan secepat mungkin dan kembali bertahan. Atlet bola basket sering melakukan sprint jarak dengan berbolak balik. Komponen dasar dari biomotor olahragawan meliputi kekuatan, ketahanan, kecepatan, koordinasi dan 
fleksibilitas.Komponen-komponen lain yang merupakan perpaduan dari beberapa komponen sehingga membentuk satu peristilahan sendiri, yaitu power merupakan gabungan dari kekuatan dan kecepatan, kelincahan merupakan gabungan dari kecepatan dan koordinasi. Komponen dasar tersebut dapat dijabarkan seperti berikut:

a. Kecepatan adalah kemampuan otot atau sekelompok otot untuk menjawab stimulus dalam waktu secepat (sesingkat) mungkin. Kecepatan merupakan salah satu komponen dasar yang harus dimiliki oleh seluruh atlet cabang olahraga khususnya cabang olahraga bola basket dalam mendukung upaya pencapaian prestasi. Latihan kecepatan dilakukan setelah atlet dilatih ketahanan dan kekuatan sesuai dengan piramida latihan.

b. Daya ledak (power) adalah hasil kali dari kekuatan dan kecepatan. Menurut Harre yang dikutip oleh Suharjana( 2013: 144), daya ledak merupakan kemampuan mengatasi tahanan dengan kecepatan tinggi. Bompa (1994), mendefinisikan daya ledak sebagai hasil kali dari kekuatan maksimum dan kecepatan maksimum. Berdasarkan ciri-ciri gerak dalam olahraga ada dua macam power, yaitu power siklis dan power asiklis. Power siklis adalah suatu gerakan kuat dan cepat yang dilakukan berulang-ulang dalam bentuk yang sama, misalnya gerakan berlari, berenang, balap sepeda, sepatu roda.Sedangkan power asiklis adalah suatu gerakan yang kuat dan cepat seperti melempar, melompat, meloncat, memukul, menendang dan semua jenis olahraga yang membutuhkan tolakan seperti basket, bulutangkis, bola voli.

c. Koordinasi adalah kemampuan menjalankan tugas gerak dengan melibatkan unsur mata, tangan dan kaki. Koordinasi merupakan hasil perpaduan antara kinerja dari kualitas otot, tulang, dan persendian dalam menghasilkan satu gerak yang efektif dan efisien. Semua cabang olahraga membutuhkan koordinasi yang baik seperti bola voli, softball dan bola basket.

\section{METODE PENELITIAN}

Penelitian ini adalah penelitian deskriptif persentase dan metode yang digunakan dalam penelitian ini adalah metode survei dengan teknik tes dan pengukuran untuk mengambil data. Populasi dalam penelitian ini adalah semua atlet pada tim basket putra SMA Negeri 4 Yogyakarta yang berjumlah 22 orang. Teknik pengambilan sampel yang digunakan dalam penelitian ini adalah purposivesampling. Sampel penelitian ini ditentukan dengan beberapa ketentuan yaitutim inti basket putra SMA Negeri 4 Yogyakarta, pada saat melakukan tes dan pengukuran dalam keadaan sehat jasmani dan rohani,umur 16-18 tahun, rutin mengikuti 
latihan selama 6 bulan atau lebih, dapat mengikuti semua prosedur tes. Berdasarkan ketentuan tersebut, peneliti memperoleh jumlah sampel sebanyak 15 orang.

Instrumen yang digunakan untuk mengukur persepsi kelelahan atlet adalah instrumen skala RPE (Rating of Perceived Exertion). Skala Borg diperkenalkan oleh Gunnar Borg dengan skala 6 - 20. Borg kemudian membuat category $(\mathrm{C})$ dan ratio $(\mathrm{R})$ menjadi Skala Borg CR10. Skala Borg CR10 digunakan untuk diagnosis sesak nafas, nyeri dada, nyeri otot tulang. Skala Borg dengan skala 6 - 20 digunakan dengan mengikuti denyut jantung orang dewasa yang sehat dengan mengalikan 10. Misalnya tenaga yang dirasakan 12, diperkirakan memiliki denyut jantung 120 denyut per menit. Skala 6 artinya tidak ada tenaga sama sekali dan skala 20 artinya tenaga maksimal. Semakin besar skala semakin besar juga tenaga yang dikeluarkan.

Responden melakukan multistage fitness test dan diukur skala RPE setelah melakukan tes. Seminggu kemudian responden melakukan yo-yo intermittend recovery test dan diukur skala RPE setelah melakukan tes. Skala RPE ini akan menjabarkan persepsi atlet terhadap tingkat kelelahan pada multistage fitness test dan yo-yo intermittend recovery test.

1. Multistage fitness test. Instrumen ini mengukur daya tahan paru jantung atlet dalam melakukan lari multi stage, kemudian jumlah balikan yang diperoleh dikonversikan ke dalam tabel untuk mendapatkan prediksi VO2Max dan dikategorikan ke dalam tabel konversi.

2. Yo-yo intermittend recovery test. Instrumen yang digunakan adalah yo-yo intermittend recovery test level 1 yang bertujuan untuk mengukur daya tahan paru jantung atlet, kemudian jarak yang diperoleh dihitung menggunakan rumus yo-yo intermittend recovery test level 1 untuk mendapatkan VO2Max, kemudian dikonversikan ke dalam tabel.

\section{HASIL PENELITIAN}

Penelitian ini menghasilkan dua data yang diperoleh dari tes daya tahan paru jantung menggunakan tes metodemultistage fitness test dan yo-yo intermittend recovery test. Peserta melakukan tes dengan metode tes daya tahan paru jantung tersebut dan peserta mengukur indeks kelelahan menggunakan skala kelelahan rating of percieved exertion (RPE) dari Bjorg.Hasil penelitian persepsi atlet terhadap tingkat kelelahan pada multistage fitness test dan yo-yo intermittend recovery test di tim basket putra SMA Negeri 4 Yogyakarta yang diperoleh dari 13 responden akan dideskripsikan sebagai berikut. 


\section{Indeks Persepsi Kelelahan (Rating of Perceived Exertion)}

Indeks kelelahan pada penelitian ini dilakukan dengan menggunakan skala kelelahan rating of percieved exertion (RPE) yang digunakan oleh Bjorg. Skala yang digunakan dimulai dari skala 6 (tidak merasakan lelah sama sekali) sampai skala 20 (sangat, sangat berat tak tertahankan). Peserta tes mengukur indeks kelelahan terhadap kedua tes tersebut dengan memilih skala yang sesuai dengan persepsi kelelahan yang dirasakan oleh peserta.

a. Indeks persepsi kelelahan atlet terhadap tes daya tahan paru jantung metode multistage fitness test. Data yang dihasilkan berdasarkan tes daya tahan paru jantung metode multistage fitness test menunjukkan rata-rata berada pada skala 14,2. Data di bawah ini menunjukkan dari atlet yang mengikuti tes daya tahan paru jantung metode multistage fitness test berjumlah 13 atlet yang terdiri dari beberapa skala yaitu skala 11 (ringan) berjumlah 1 orang $(7,7 \%)$, skala 13 (sedang) berjumlah 4 orang $(30,8 \%)$, skala 15 (berat) berjumlah 7 orang $(53,8 \%)$, skala 17 (sangat berat) berjumlah 1 orang $(7,7 \%)$.

b. Indeks persepsi kelelahan atlet terhadap tes daya tahan paru jantung metode yo-yo intermittend recovery test. Data yang dihasilkan berdasarkan tes daya tahan paru jantung metode yo-yo intermittend recovery test menunjukkan rata-rata berada pada skala 14,4 . Data di bawah ini menunjukkan hasil tes daya tahan paru jantung metode yo-yo intermittend recovery test berjumlah 13 atlet yang terdiri dari beberapa skala yaitu skala 13 (sedang) berjumlah 5 orang $(38,4 \%$ ), skala 15 (berat) berjumlah 7 orang $(53,8 \%)$, skala 17 (sangat berat) berjumlah 1 orang $(7,7 \%)$.

c. Indeks persepsi kelelahan atlet terhadap tes daya tahan paru jantung metode multistage fitness test dan yo-yo intermittend recovery test Indeks persepsi kelelahan atlet terhadap tes daya tahan paru jantung menggunakan metode multistage fitness test dan yo-yo intermittend recovery test disajikan pada tabel berikut ini. Dari data di atas dapat dijelaskan persepsi atlet terhadap tes daya tahan paru jantung dengan metode multistage fitness test yang diikuti oleh 13 atlet terdiri dari beberapa skala kelelahan (RPE) yaitu skala 11 (ringan) berjumlah 1 orang (7,7\%), skala 13 (sedang) berjumlah 4 orang (30,8\%), skala 15 (berat) berjumlah 7 orang (53,8\%), skala 17 (sangat berat) berjumlah 1 orang $(7,7 \%)$ dan persepsi atlet terhadap tes daya tahan paru jantung dengan metode yo-yo intermittend recovery testterdiri dari beberapa skala kelelahan (RPE) yaitu skala 13 (sedang) berjumlah 5 orang (38,5\%), skala 15 (berat) berjumlah 7 orang $(53,8 \%)$, skala 17 (sangat berat) berjumlah 1 orang $(7,7)$. 
Berdasarkan dari hasil data tersebut dapat dilihat persepsi kelelahan atlet terhadap multistage fitness test lebih rendah daripada yo-yo intermittend recovery test dikarenakan persepsi kelelahan atlet terhadap yo-yo intermittend recovery test tidak ada yang berada pada skala 11 (ringan).

\section{Hasil Daya Tahan Paru Jantung (VO2Max)}

Data yang diperoleh dari tes daya tahan paru jantung dengan menggunakan metode multistage fitness test adalah data level dan shuttle yang kemudian dikonversikan dengan tabel nilai prediksi yang sudah divalidasi dan diadopsi oleh Sukadiyanto Dosen Fakultas Ilmu Keolahragaan Universitas Negeri Yogyakarta, sedangkan pada yo-yo intermittend recovery test data yang diperoleh adalah total jarak yang ditempuh peserta yang dikalkulasi menggunakan rumus VO2max dari Bangsbo, dkk. (2008). Data VO2max dari masing-masing tes kemudian dikategorikan menggunakan tabel VO2Max dari Heywood (1998). Hasil penelitian tingkat daya tahan paru jantung atau VO2Max menggunakan multistage fitness test dan yo-yo intermittend recovery test pada tim basket putra SMA Negeri 4 Yogyakarta sebagai berikut.

a. Tingkat Daya Tahan Paru Jantung atau VO2Max atlet terhadap metode multistage fitness test. Data di bawah ini menunjukkan dari atlet yang mengikuti tes daya tahan paru jantung metode multistage fitness test berjumlah 13 atlet yang terdiri dari beberapa kategori yaitu kategori rendah berjumlah 2 orang $(15,4 \%)$, kategori sedang berjumlah 5 orang $(38,4 \%)$, kategori baik berjumlah 5 orang $(38,4 \%)$, kategori sangat baik berjumlah 1 orang $(7,7 \%)$.

b. Tingkat Daya Tahan Paru Jantung atau VO2Max atlet terhadap metode yo-yo intermittend recovery test. Data di bawah ini menunjukkan dari atlet yang mengikuti tes daya tahan paru jantung metode yo-yo intermittend recovery test berjumlah 13 atlet yang terdiri dari beberapa kategori yaitu kategori sedang berjumlah 5 orang $(38,4 \%)$, kategori baik berjumlah 7 orang $(53,8 \%)$, kategori sangat baik berjumlah 1 orang $(7,7)$.

c. Tingkat daya tahan paru jantung atau VO2Max terhadap tes daya tahan paru jantung metode multistage fitness test dan yo-yo intermittend recovery test berdasarkan dari hasil data dapat dilihat tingkat daya tahan paru jantung atau VO2Max terhadap tes metode multistage fitness test lebih rendah daripada yo-yo intermittend recovery test dikarenakan tingkat daya tahan paru jantung atau VO2Maxterhadap tes metodeyo-yo intermittend recovery test tidak ada yang berada pada kategori sangat rendah dan rendah. 


\section{PEMBAHASAN}

Berdasarkan dari hasil penelitian dapat dilihat tingkat daya tahan paru jantung atau VO2Max atlet terhadap multistage fitness test lebih rendah daripada yo-yo intermittend recovery test dikarenakan tingkat daya tahan paru jantung atau VO2Max atlet terhadap yo-yo intermittend recovery test tidak ada yang berada pada kategori rendah dan rendah sekali. Daya tahan paru jantung atau VO2Max menjadi faktor utama dalam permainan bola basket. Permainan bola basket mengharuskan pemain bermain dengan explosive secara intermittend sehingga perlu adanya dorongan dari daya tahan paru jantung yang baik. Permainan bola basket dilakukan selama 10 menit dalam 4 babak, sehingga menuntut para pemain untuk bermain dengan sangat cepat dalam menyetak angka.

Berdasarkan dari data hasil penelitian indeks persepsi kelelahan yang telah dijabarkan di atas, dapat dilihat indeks persepsi kelelahan atlet terhadap metode multistage fitness test lebih rendah daripada metode yo-yo intermittend recovery test. Namun, daya tahan paru jantung atau VO2Max atlet terhadap tes metode yo-yo intermittend reovery test lebih tinggi daripada tes metode multistage fitness test. Berdasarkan dari hasil data tingkat daya tahan paru jantung yang telah dijabarkan dapat dilihat tingkat daya tahan paru jantung atau VO2Max atlet terhadap multistage fitness test lebih rendah daripada yo-yo intermittend recovery test dikarenakan tingkat daya tahan paru jantung atau VO2Max atlet terhadap yo-yo intermittend recovery test tidak ada yang berada pada kategori rendah dan rendah sekali.

\section{KESIMPULAN}

Ilmu dan teknologi akan selalu mengalami perkembangan untuk disempurnakan dan tentunya untuk mempermudah manusia dalam melakukan pekerjaan. Tes dan pengukuran daya tahan paru jantung juga mengalami perkembangan seperti pada multistage fitness test dan yo-yo intermittend recovery test. Yo-yo intermittend recovery test sesuai dilakukan pada olahraga yang intermittend seperti bola basket. Tes daya tahan paru jantung aerobik harus menggunakan tipe latihan yang sama dilakukan oleh peserta dengan waktu umum sekitar 815 menit, jika lebih pendek dan meningkatkan energi anaerobik maka tes ini akan kurang valid.

Yo-yo intermittend recovery test adalah tes daya tahan paru jantung yang dikembangkan dari multistage fitness test pada tahun 2008 oleh Bangsbo sehingga tes tersebut tidak banyak diketahui oleh atlet. Pengetahuan atlet yang kurang terhadap tes tersebut mempengaruhi 
persepsi seseorang dipengaruhi oleh: Frame of Reference, yaitu kerangka pengetahuan yang dimiliki dan dipengaruhi dari pendidikan, bacaan, penelitian, serta Frame of Experience, yaitu pengalaman yang telah dialaminya yang tidak terlepas dari keadaan lingkungan sekitarnya. Yo-yo intermittend recovery test memiliki recovery aktif yang tidak dimiliki oleh multistage fitness test.Yo-yo intermittend recovery test sesuai dengan tipe latihan yang dilakukan pada permainan bola basket yang memiliki recovery aktif diantara permainan yang explosive. Tipe latihan yang sama dengan yo-yo intermittend recovery test mempengaruhi tingkat daya tahan paru jantung, faktor latihan dapat meningkatkan fungsi dan kapasitas sistem respirasi, kardiovaskuler, dan volume darah, tetapi perubahan yang paling penting terjadi pada serat otot yang digunakan dalam latihan. Serat otot yang mengalami perubahan tersebut membuat atlet lebih mudah untuk melakukan tes daya tahan paru jantung dengan metode yo-yo intermittend recovery testsehingga mendapatkan tingkat VO2Max yang lebih tinggi.

\section{DAFTAR PUSTAKA}

Castagna, C.,Impellizzeri, F.M.,Chamari, K.,Carlomagno, D.,\& Rampinini, E.(2006). Aerobic Fitnessand Yo- yo Continuous and Intermittent Tests Performances in Soccer Players: A Correlation Study. Journal of Strength \& Conditioning Research20 (2):320-325.

Kardiansyah. (2012). Hubungan Persepsi Karyawan terhadap Penerapan Program Keselamatan dan Kesehatan Kerja dengan Produktivitas Kerja di PT X. Skripsi. Yogyakarta: UII.

Kavcic,L.,Milic,R.,Jourkesh.,Ostojic,S. M.,Ozkol, M.Z. (2012). Comparative Study of Measured anda Predicted VO2Max during A Multistage Fitness Test with Junior Soccer Players. Journal Kinesiologi 441:18-23

Novita Intan Arovah, Eka Novita Indra, dkk. (2010).Circulomassage, Recovery, Pasif dan Aktif untuk Meningkatkan Klirens Laktat, Stabilitas Performa Anaerobik dan Menurunkan Indeks Kelelahan (Rating of Perceived Exertion). Laporan PenelitianPengembangan IPTEK Olahraga dengan Perguruan Tinggi. Yogyakarta: FIK UNY.

PERBASI. (2010). Peraturan Resmi Bola Basket 2010. Diakses dari http://brosoppemalang.blogspot.com/2012/06/fi ba-peraturan-resmi-bola- basket.html, pada tanggal 3 Februari2015,pukul22.19WIB.

Sadoso Sumosardjuno. (1980). Perubahan Fisiologis karena Latihan Fisik. Yogyakarta: FIK UNY.

Santosa Giriwijoyo \& Dikdik Zafar Sidik. (2012). Ilmu Kesehatan Olahraga. Bandung: 
Remaja Rosdakarya. 